\title{
Airway foreign body occurs unintentionally during anesthetic management of patient with asthma
}

\author{
By Woo Jin Cho ${ }^{1}$, So Hui Yun ${ }^{1,2}$, Yun Suk Choi ${ }^{1,2}$, Bang Won Lee ${ }^{1}$, Mi Ok Kim ${ }^{3}$, \\ Jong Cook Park ${ }^{1,2, \mathbb{}}$ \\ ${ }^{1}$ Department of Anesthesiology and Pain Medicine, Jeju National University Hospital \\ ${ }^{2}$ Department of Anesthesiology and Pain Medicine, Jeju National University School of Medicine \\ ${ }^{3}$ Division of Pulmonary, Department of Internal Medicine, Jeju National University Hospital, \\ Jeju National University School of Medicine
}

\begin{abstract}
Intraoperative delivery of salbutamol ( $\beta_{2}$ agonist) through a breathing circuit may be performed in asthma patient. A 28-year-old woman with a history of asthma was diagnosed with chronic sinusitis and bilateral nasal polyps, and an endoscopic sinus surgery was performed. The patient was recommended salbutamol nebulization every 4 hours during the perioperative period because of the risk of asthma attack. At the end of the operation, when salbutamol was sprayed through the tube before extubation and the connector tip went inside the tube during injection. The patient was immediately referred to the pulmonary medicine department for bronchoscopy, where the foreign body was removed safely without any complications. When general anesthesia is performed on a patient who usually uses an inhaler for asthma, caution is required because the tip that connects the inhaler and the breathing circuit can aspirate into the endotracheal tube and enter the lungs when applying the inhaler before waking up the patient.
\end{abstract}

Key words: Adrenergic beta 2 receptor agonists, Airway obstruction, Bronchial asthma, Foreign body

\section{INTRODUCTION}

Nasal drug delivery of salbutamol ( $\beta_{2}$ agonist) through a circuit may be performed in a patient during surgery under general anesthesia. In this situation, if a connector manufactured arbitrary by the hospital is used without a commodifying connector, the instability of the device itself may introduce a foreign body in the airway.

Received: June 13, 2019; Revised: July 4, 2019; Accepted: July 7, 2019 $\triangle$ Correspondence to : Jong Cook Park

Department of Anesthesiology and Pain Medicine, Jeju National University School of Medicine, Aran 13 gil 15, Jeju-si, Jeju Special Self-Governing Province 63241, Republic of Korea

Tel: 82-64-717-2028, FAX: 82-64-717-2042

E-mail: pjcook@jejunu.ac.kr

\section{CASE REPORT}

A 28-year-old woman with a history of asthma was admitted to our hospital. The patient was diagnosed with chronic sinusitis with bilateral nasal polyps. Therefore, an endoscopic sinus surgery was planned. The patient had asthma and acetaminophen cross-sensitivity with nasal stuffiness due to aspirin hypersensitivity; hence, the pulmonary medicine department was consulted preoperatively. As the patient had recently suffered an asthma attack, salbutamol nebulization every 4 hours was recommended. Preoperative laboratory results were as follows: $6,600 / \mu \mathrm{L}$ white blood cells and $15.7 \%$ eosinophils, showing eosinophilia. We used sevoflurane during inhalation anesthesia for its bronchodilatory effect. The operation time was 3 hours and 20 minutes, without any specific events. We 

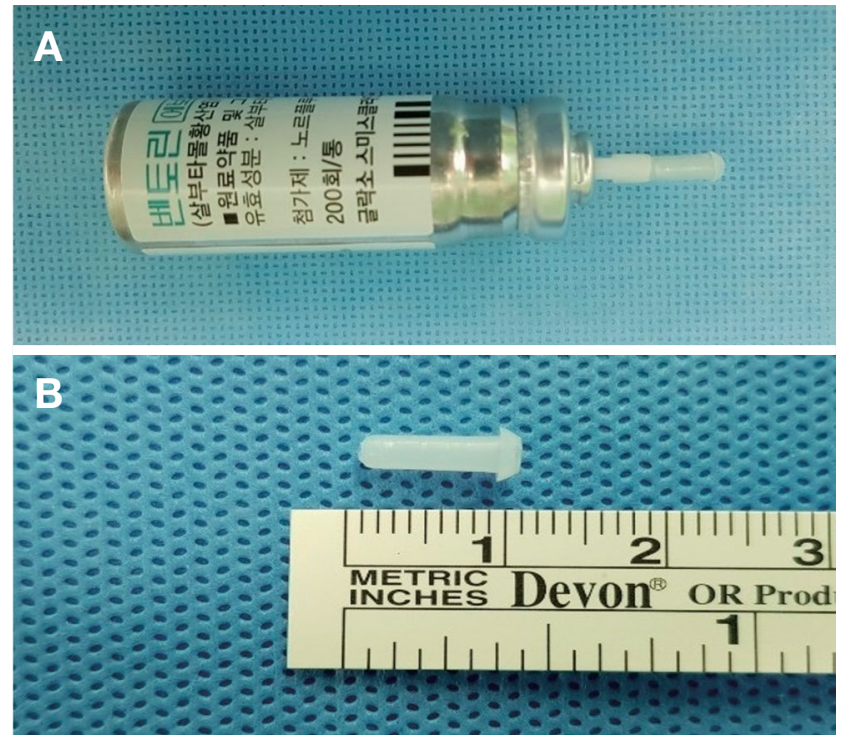

Figure 1. Self-manufactured connector system: Salbutamol is connected to the intravenous connector tip via a cut in the intravenous line. The connector tip is a $1 \mathrm{~cm}$ long material with an internal diameter(A: Complex of Salbutamol with connector, B: connector tip).

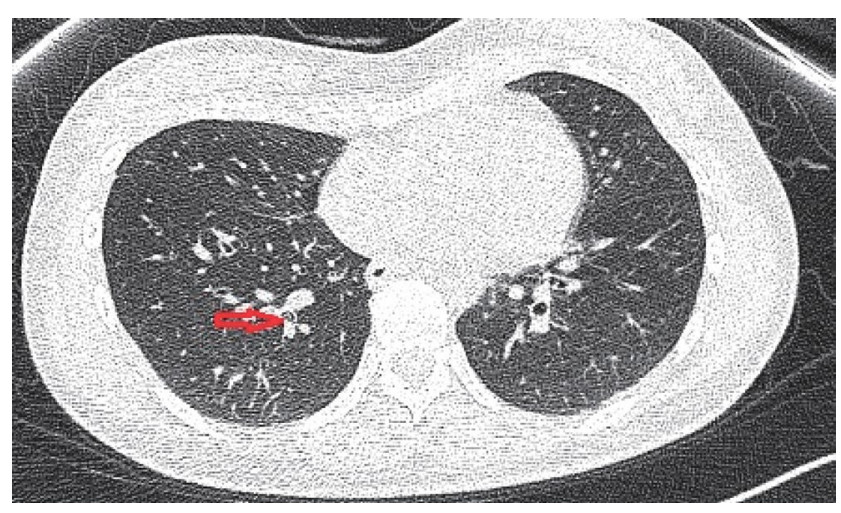

Figure 2. Postoperative chest computed tomography shows focal tubular lesion within the the posterobasal segmental bronchus in the right lower lobe. The arrow indicates lesion that is presumed to be a foreign body.

used salbutamol (Ventolin Evohaler ${ }^{\circledR}$, GlaxoSmithKline, Spain; 200 doses/18.0 g; Fig. 1A) to prevent asthma attacks during anesthetic emergence. We used a self-manufactured connector to connect it to the circuit (Fig. 1B). When the salbutamol inhaler was removed from the circuit after one spray, the connector tip was disappeared and was thought to have entered the airway. Even after tube suction, the connector tip could not be retrieved. Thereafter, a bronchoscope was used to check the endotracheal tube and carina, but the connector tip could not be found. To confirm the

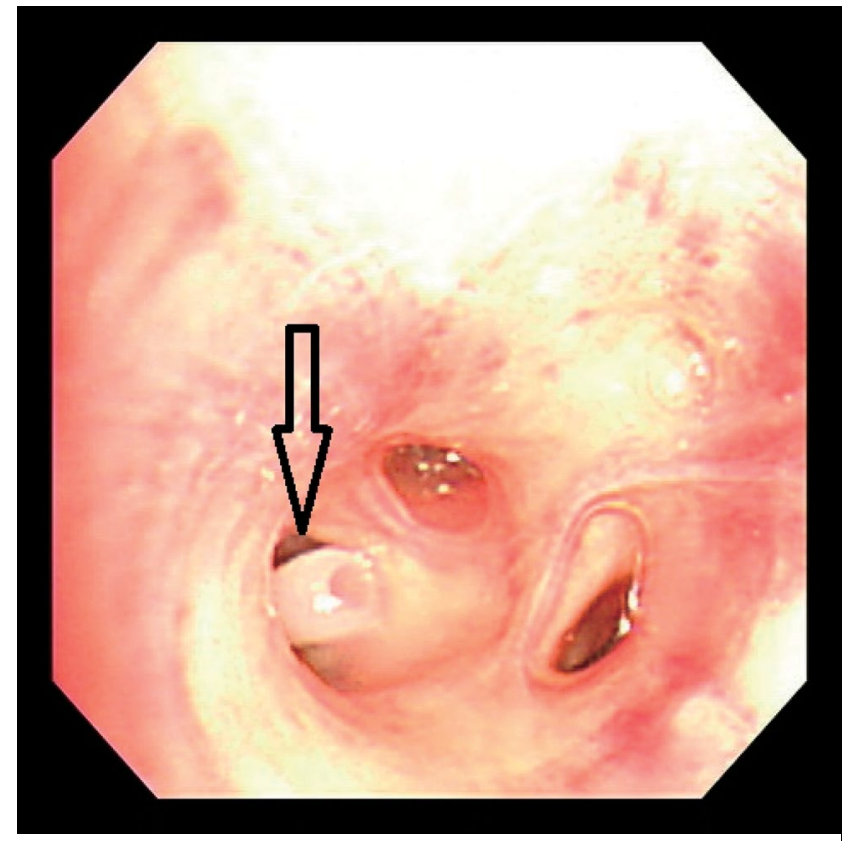

Figure 3. As a result of the bronchoscope, a foreign body is found at the entrance of the posterobasal segment at $2^{\text {nd }}$ branch of the right lower lobe. The arrow points to foreign body.

foreign body in the airway, we conducted chest radiography with a portable machine in the operating room, which showed no specific findings. For further evaluation, chest computed tomography (CT) was performed after the end of anesthesia. Chest CT findings showed a foreign body in the bronchus of the right lower lobe (Fig. 2), and a pulmonary medicine specialist immediately used a bronchoscope (BF TYPE 260, OLYMPUS, Japan) under regional anesthesia in the endocoscopy room to perform bronchoscopy. The foreign body was located at the entrance of the posterobasal segment at the $2^{\text {nd }}$ bronchial branch of the right lower lobe (Fig. 3) and was removed using disposable biopsy forceps (FB-231D). The patient was then transferred to the ward and discharged without any complications.

\section{DISCUSSION}

We presented the case of a foreign body introduced in the airway when using a nebulizer during general anesthesia. We have been using self-manufactured nebulizer connectors for several years without any event. In this case, complications did not occur in the patient because appropriate actions were taken immediately after the foreign 
body was confirmed in the airway.

Nebulizers are used not only for asthma but also for bronchial spasms. ${ }^{1,2)}$ Occasionally, the use of a nebulizer in the operating room can introduce foreign bodies in the airway, which can be avoided by ensuring its proper use. It is safer to use commercialized connectors when using a nebulizer. Puffing can be done during nebulization. If the use of nebulizers is not feasible, using an inhalational anesthetic agent (sevoflurane) is a good alternative. Sevoflurane also has a bronchodilatory effect. ${ }^{3)}$ In this case, sevoflurane was used for anesthetic maintenance and the nebulizer was requested in the pulmonary consultation.

The separation of the connector tip can be explained by Bernoulli's principle. ${ }^{4)}$ The Bernoulli's principle states that as air moves from a wide to a narrow space, the pressure decreases and velocity increases. Therefore, when the high-pressure aerosol was leaving the nebulizer, the unfirmly fixed connector tip got separated.

The purpose of this case report was to report the unintentional introduction of a foreign body in the airway when using a nebulizer via an endotracheal tube under general anesthesia. Often, an act performed the safety of the patient may pose a threat to the patient. Even in ways that have not been a problem in the past, it is necessary to remind once more time about the stability and safety of manual procedures.

\section{ACKNOWLEDGEMENT}

Previous presentation in conferences: This study was presented at the $95^{\text {th }}$ Annual Scientific Meeting of the Korean Society of Anesthesiologists on November 10, 2018 in Seoul, Korea.

Conflict of interest: No potential conflict of interest relevant to this article was reported.

Financial disclosure: The study was performed according to the Helsinki Declaration and approved by the Institutional Review Board (IRB no. 2019-03).

Funding/Support: None declared.

\section{REFERENCES}

1. Manthous CA, Chatila W, Schmidt GA, Hall JB. Treatment of bronchospasm by metered-dose inhaler albuterol in mechanically ventilated patients. Chest 1995;107:210-3.

2. Ram FS. Clinical efficacy of inhaler devices containing beta (2)agonist bronchodilators in the treatment of asthma: Cochrane systematic review and meta-analysis of more than 100 randomized, controlled trials. Am J Respir Med 2003;2:349-65.

3. Vaschetto R, Bellotti E, Turucz E, Gregoretti C, Corte FD, Navalesi P. Inhalational anesthetics in acute severe asthma. Curr Drug Targets 2009;10:826-32.

4. Hall N, Editor. Bernoulli's Equation [Internet]. Cleveland, $\mathrm{OH}$ : NASA Glenn Research Center; [updated 2015 May 05; cited 2019 Mar 30]. Available from: https://www.grc.nasa.gov/WWW/K-12/ airplane/bern.html. 